\title{
Seletalisib: Characterization of a Novel, Potent, and Selective Inhibitor of $\mathrm{PI} 3 \mathrm{~K} \delta^{[\mathrm{S}}$
}

\author{
Rodger A. Allen, Daniel C. Brookings, Mark J. Powell, ${ }^{1}$ Jean Delgado, \\ Lindsay K. Shuttleworth, Mark Merriman, lan J. Fahy, ${ }^{2}$ Roohi Tewari, John P. Silva, \\ Louise J. Healy, ${ }^{3}$ Gareth C. G. Davies, Breda Twomey, Rona M. Cutler, Apoorva Kotian, \\ Andrea Crosby, Gillian McCluskey, Gillian F. Watt, and Andrew Payne
}

UCB Pharma, Slough, Berkshire, United Kingdom

Received August 22, 2016; accepted March 21, 2017

\begin{abstract}
Phosphoinositide 3-kinases (PI3K) are key signaling enzymes regulating cellular survival, development, and function. Expression of the PI3K $\delta$ isoform is largely restricted to leukocytes and it plays a key role in immune cell development and function. Seletalisib is a novel small-molecule inhibitor of PI3K $\delta$ that was evaluated in biochemical assays, cellular assays of adaptive and innate immunity, and an in vivo rat model of inflammation. Our findings show that seletalisib is a potent, ATP-competitive, and selective $\mathrm{PI} 3 \mathrm{~K} \delta$ inhibitor able to block protein kinase $B(A K T)$ phosphorylation following activation of the B-cell receptor in a B-cell line. Moreover, seletalisib inhibited $N$-formyl peptide-stimulated but not phorbol myristate acetate-stimulated superoxide release from human neutrophils, consistent with a PI3K $\delta$-specific activity. No indications of cytotoxicity were observed
\end{abstract}

in peripheral blood mononuclear cells (PBMCs) or other cell types treated with seletalisib. Findings from cellular assays of adaptive immunity demonstrated that seletalisib blocks human T-cell production of several cytokines from activated T-cells. Additionally, seletalisib inhibited B-cell proliferation and cytokine release. In human whole blood assays, seletalisib inhibited CD69 expression upon B-cell activation and anti-IgE-mediated basophil degranulation. Seletalisib showed dose-dependent inhibition in an in vivo rat model of anti-CD3-antibody-induced interleukin 2 release. Collectively, these data characterize seletalisib as a selective PI3K $\delta$ inhibitor and potential therapeutic candidate for the treatment of B-cell malignancies and autoimmune diseases driven by dysregulated proinflammatory cytokine secretion.

\section{Introduction}

PI3K $\delta$ as a Therapeutic Target for Inhibition. Phosphoinositide 3-kinases (PI3Ks) are a family of enzymes that phosphorylate phosphoinositides and regulate key cellular processes that include survival, proliferation, and differentiation. Class I PI3Ks have been shown to participate in the orchestration of signaling events that lead to immune cell development, with specific functional effects in individual celllineage subsets (Okkenhaug, 2013a). The PI3K $\alpha$ and PI3K $\beta$ isoforms are ubiquitously expressed, whereas expression of $\mathrm{PI} 3 \mathrm{~K} \gamma$ and $\mathrm{PI} 3 \mathrm{~K} \delta$ is enriched in leukocytic cells compared with other cell types, implying a more specific and important role in leukocyte development and function (Ji et al., 2007;

The studies were funded by UCB Pharma. Medical writing and editorial support was funded by UCB Pharma. All authors are current or former employees of UCB Pharma and may hold stock options in UCB Pharma

${ }^{1}$ Current affiliation: Immunocore Limited, Abingdon, UK.

${ }^{2}$ Current affiliation: Beckman Coulter, High Wycombe, UK.

${ }^{3}$ Current affiliation: Aurelia Bioscience, Nottingham, UK

https://doi.org/10.1124/jpet.116.237347.

S This article has supplemental material available at jpet.aspetjournals.org.
Banham-Hall et al., 2012; Okkenhaug, 2013a). Although $\mathrm{PI} 3 \mathrm{~K} \gamma$ and $\mathrm{PI} 3 \mathrm{~K} \delta$ have similar cellular distributions, they are differentially coupled in specific cells. PI3K $\gamma$ is generally coupled to G protein-coupled receptors (GPCRs), including leukotriene and chemokine receptors, and plays a particularly important role in chemokine-mediated recruitment and the activation of innate immune cells at sites of inflammation (Rommel et al., 2007; Okkenhaug, 2013a; Hawkins and Stephens, 2015). In contrast, PI3K $\delta$ signals predominantly downstream of several immune receptor tyrosine kinases, including the T-cell receptor (TCR), the B-cell receptor (BCR), and the high-affinity IgE receptor Fc epsilon receptor 1 (FceR1), thereby playing a greater role in the acquired immune response (Bilancio et al., 2006; Al-Alwan et al., 2007; Okkenhaug et al., 2007, 2014; Costa et al., 2011; Bartok et al., 2012; Hawkins and Stephens, 2015).

Selective expression of PI3K $\delta$ in leukocytes provides a rationale for investigating this isoform as a therapeutic target for diseases featuring pathologic activation of the PI3K $\delta$ pathway in hematopoietic cells, including B-cell malignancies and immune and inflammatory disorders such as rheumatoid

ABBREVIATIONS: APC, allophycocyanin; BCR, B-cell receptor; BSB, basophil stimulation buffer; CFSE, carboxyfluorescein $N$-succinimidyl ester; $\mathrm{Cl}$, confidence interval; DMSO, dimethyl sulfoxide; ELISA, enzyme-linked immunosorbent assay; FBS, fetal bovine serum; FceR1, Fc epsilon receptor 1; fMLP, $N$-formyl-peptides; FRET, fluorescence resonance energy transfer; GPCR, G protein-coupled receptors; HDM, house dust mite; MSD, Meso Scale Diagnostics; PBMC, peripheral blood mononuclear cells; PBS, phosphate-buffered saline; PI3K, phosphoinositide 3-kinases; PMA, phorbol myristate acetate. 
arthritis, asthma, psoriasis, and systemic lupus erythematosus (Foster et al., 2012; Somoza et al., 2015; Stark et al., 2015). Lymphocyte developmental defects, attenuated signaling by antigen receptors, B-cell functional defects, and decreased T-cell-dependent responses are observed in mice that lack or express mutant $\mathrm{p} 110 \delta$, the catalytic subunit of PI3K $\delta$ (Clayton et al., 2002; Jou et al., 2002; Okkenhaug et al., 2002; Hebeis et al., 2004). Moreover, it has been demonstrated that lipopolysaccharide-induced functions of B-cells in mice require PI3K activity mediated primarily via the $\mathrm{p} 110 \delta$ catalytic subunit (Hebeis et al., 2004).

There is evidence that B-cell-mediated presentation of antigens to T-cells is a key process underlying the initiation and amplification of autoimmune diseases (Puri and Gold, 2012). Inhibition of PI3K $\delta$ activity prevents B-cell migration, adhesion, survival, activation, and proliferation, which diminishes the capacity for B-cell-mediated presentation to autoreactive T-cells (Puri and Gold, 2012). This results in nonactivation of autoreactive T-cells and subsequent reduced secretion of autoantibodies and proinflammatory cytokines.

Although $\mathrm{PI} 3 \mathrm{~K} \delta$ activity has been shown to be required for normal immune cell development and function, inherited gain-of-function mutations in the $\mathrm{p} 110 \delta$ protein are associated with recently described primary immunodeficiency conditions in humans that can increase susceptibility to bacterial and viral infections (Angulo et al., 2013; Deau et al., 2014; Lucas et al., 2014). The apparently paradoxical outcome of both lossof-function and gain-of function mutations in PI3K $\delta$ leading to immune cell defects and immunosuppression has been proposed to result from a requirement for specific cellular and temporal regulation of PI3K $\delta$ activity for normal immune cell development (Lucas et al., 2016). Enhanced activation of PI3K has been identified in peripheral blood T-cells from patients with systematic lupus erythematosus (Suarez-Fueyo et al., 2011) and is believed to account for vascular dysfunction observed in a mouse model of type- 1 diabetes (Pinho et al., 2010). This raises the possibility that selective PI3K $\delta$ inhibitors may provide a viable alternative therapeutic approach to treating immune-inflammatory diseases. Indeed, the potential for such a role has been enhanced by evidence that PI3K $\delta$ inhibition can be achieved not only in naïve T-cells but also in previously activated memory T-cells from healthy and allergic donors and from patients with spondyloarthritis (Soond et al., 2010). The potential for inhibition of PI3K $\delta$ to result in undesirable on-target pharmacology, including gut inflammation (Okkenhaug et al., 2002) and defective responses to infection (Gracias et al., 2016), came from studies with kinase-inactive p110 knock-in animals. Data from clinical studies with PI3K $\delta$ inhibitors are becoming available and a better defined picture of the effects of PI3K $\delta$ blockade will emerge in the coming years. Interestingly, topline results from two phase II studies of duvelisib, a selective PI3K $\delta / \gamma$ inhibitor administered across different low-dose ranges, suggest poor efficacy in the immuneinflammatory setting (Infinity Pharmaceuticals, 2014, 2015). However, in the oncology setting, phase I studies evaluating higher-dose duvelisib in patients with advanced hematologic malignancies (including relapsed/refractory indolent non-Hodgkin lymphoma) or treatment-naïve chronic lymphocytic leukemia have observed clinical activity (Flinn et al., 2014; Patel et al., 2015).

Seletalisib, $N$-[(1R)-1-[8-chloro-2-(1-oxidopyridin-1-ium-3yl)-3-quinolyl]-2,2,2-trifluoro-ethyl]pyrido[3,2-day]pyrimidin- 4-amine, is a novel small-molecule quinolone-based selective $\mathrm{PI} 3 \mathrm{~K} \delta$ inhibitor with potential as an oral agent for the treatment of a range of immune-inflammatory diseases. The medicinal chemistry program leading to the discovery of seletalisib will be described elsewhere in due course. In this article, we present the studies of the biochemical and biologic profile of seletalisib to demonstrate its potency and selectivity as a $\mathrm{PI} 3 \mathrm{~K} \delta$ inhibitor.

\section{Materials And Methods}

Compound Handling, Blood Donation, and Data Analysis. Figure 1 shows the structure of seletalisib. For in vitro assays, compounds were made up from solid as a $10 \mathrm{mM}$ stock in dimethyl sulfoxide (DMSO; Sigma-Aldrich, Poole, UK). Serial dilutions were carried out in DMSO. Compounds were prediluted into assay buffer (biochemical assays) or media (cellular assays) prior to addition to the final assay wells or tubes. Human blood samples were obtained under a license (\#12504) granted to UCB under Section 16 (2) (e) (ii) of the Human Tissue Act (UK) and all donors provided their written consent to participate. Donated samples were anonymized and came from working-age individuals from the in-house UCB blood donation service. The concentration of DMSO was maintained in all treated and control wells at $0.1 \%(\mathrm{v} / \mathrm{v})$ unless otherwise stated. Concentration-response curves were analyzed using four-parameter logistic curve using XLfit or GraphPad Prism (version 6.01) software.

In Vitro Kinase Activity Assays and Off-Target Profiling. The activities of seletalisib and the pan-PI3K inhibitor UCB1370037 (Hutchinson et al., 2008) were tested in biochemical kinase assays of the PI3K $\alpha$, PI3K $\beta$, PI3K $\delta$ (EMD Millipore, Darmstadt, Germany), and $\mathrm{PI} 3 \mathrm{~K} \gamma$ (manufactured in-house) isoforms. Competitive time-resolved (TR) fluorescence resonance energy transfer (FRET) assays using a four-step PI3K assay reagent kit (EMD Millipore) were performed according to manufacturer instructions. In this assay, PI3K activity is measured by the detection of phosphatidylinositol triphosphate (PIP3) as follows: A complex is formed between biotinylated PIP3 and a glutathione $S$-transferase (GST)-tagged pleckstrin homology-domain protein, which are detected by streptavidin-allophycocyanin (APC) and europium-labeled anti-GST antibody, respectively. Proximity of the two fluorophores results in a stable TR-FRET signal. The production of unlabeled PIP3 by PI3K in the kinase reaction results in competitive inhibition of the complex and therefore the FRET signal. Briefly, $2 \mu \mathrm{l}$ of compound was added to wells containing $8 \mu \mathrm{l}$ of a mixture containing phosphatidylinositol bisphosphate (PIP2) substrate and ATP (Roche, Burgess Hill, UK), before addition of $10 \mu \mathrm{l}$ of PI3K (prediluted to the required concentration). The final assay concentrations of ATP and PIP2 substrate were $2 \mu \mathrm{M}$ and $10 \mu \mathrm{M}$, respectively. The final assay concentration of PI3K enzymes was 1-8 $\mathrm{nM}$ depending on batch activity. The final assay concentration of DMSO was $2.0 \%$. The plate was incubated at room temperature for 30 minutes before addition of stop buffer and detection buffer according to manufacturer instructions, and the plate was then incubated for a further 6 hours at room temperature. TR-FRET measurements were performed on an Analyst GT plate reader (330 nm excitation filter, 615/665-nm emission filters; Molecular Devices, Wokingham, UK). The ATP concentration dependence of the activity of seletalisib against PI3K $\delta$ was established by running the assay in the presence of varying ATP concentrations (2, 40, 200, and $1000 \mu \mathrm{M})$. The final assay concentrations of PI3K $\delta$ and PIP2 substrate in these assays were $1 \mathrm{nM}$ and $25 \mu \mathrm{M}$, respectively.

The kinase selectivity of seletalisib was assessed using the SelectScreen FRET-based biochemical profiling service provided by Life Technologies, Paisley, UK. A screening concentration of $10 \mu \mathrm{M}$ was selected to assess a concentration several orders of magnitude above the active concentration of seletalisib against its target in biochemical and cellular systems. This concentration is commonly 


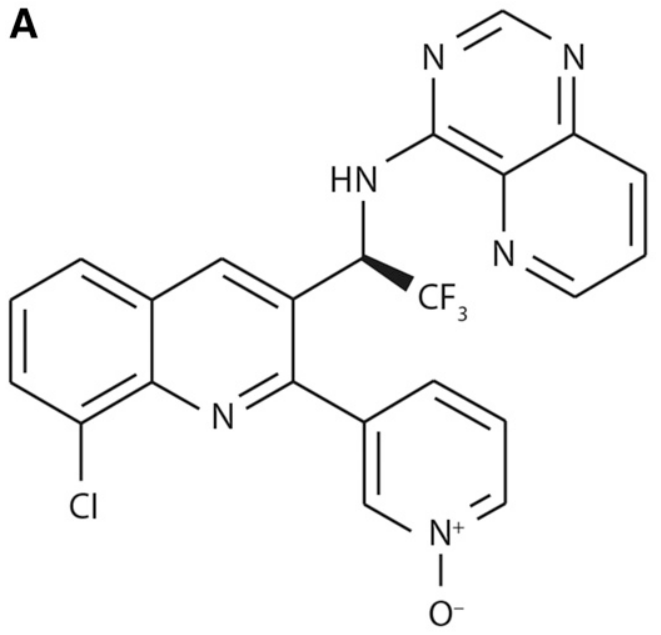

B

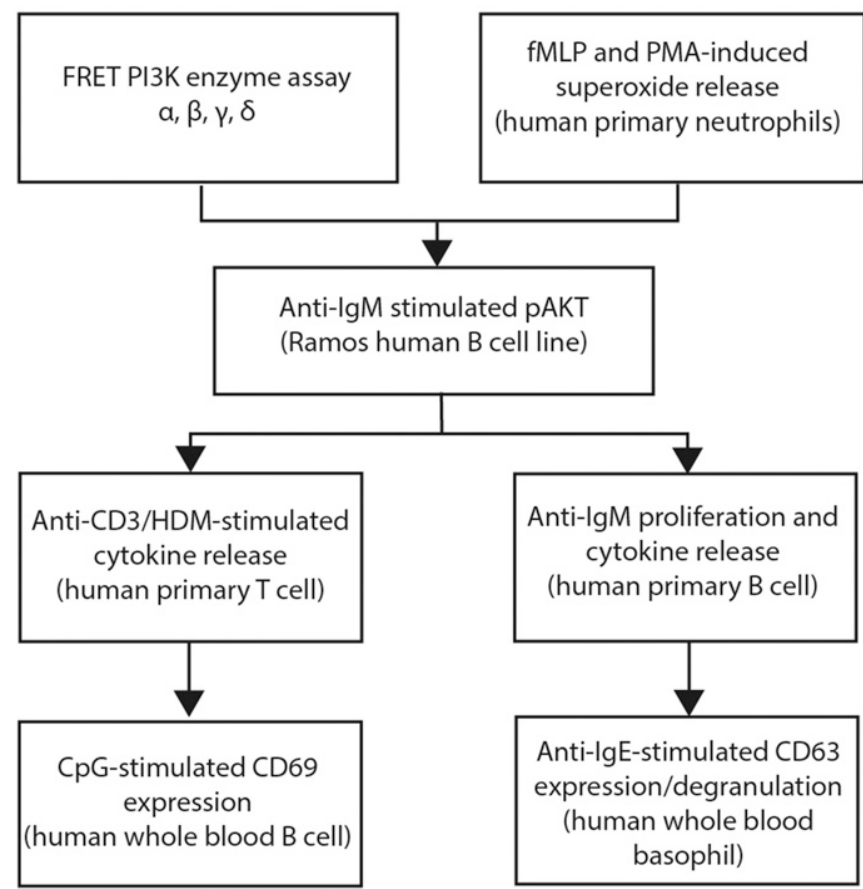

Fig. 1. (A) Structure of the PI3K $\delta$ inhibitor, seletalisib. (B) The in vitro activity cascade employed to discover seletalisib. Assays are described in detail in Materials and Methods. The first tier assays determined the primary potency and selectivity of compounds in biochemical and cellular assays. The pAKT-expression assay in Ramos cells was used to confirm potency in a target-proximal system. Tier 3 and 4 assays assessed functional activity in human primary cell assay systems with isolated PBMCs and whole blood, respectively.

used in secondary pharmacology studies to understand potential offtarget activity (Bowes et al., 2012). Seletalisib was screened against a panel of kinases using the Z'-LYTE FRET and the Adapta Universal Kinase Assays (Thermo Fisher Scientific, Waltham, MA) according to manufacturer's protocols. In the Z'-LYTE FRET primary reaction, the $\gamma$-phosphate of ATP is transferred to a synthetic FRET peptide labeled with coumarin (donor) and fluorescein (acceptor). Subsequently, nonphosphorylated peptide is cleaved by a site-specific protease, disrupting FRET between donor and acceptor, and allowing measurement of the kinase reaction. Kinase activity is measured in Adapta assays by the production of ADP. Following the enzyme reaction, europiumlabeled anti-ADP antibody and an Alexa-Fluor 647-labeled ADP tracer are added to the assay well, generating a TR-FRET signal. ADP formed in the kinase reaction will displace the labeled ADP tracer, allowing kinase activity to be determined.

The binding of seletalisib to a range of nonkinase enzymes, receptors and ion channels was assessed at Cerep (Celle L'Evescault, France). In each experiment the reference compound was tested concurrently with seletalisib and the data were compared with historical values determined at Cerep. The assays were undertaken in accordance with Cerep's standard operating procedures. In brief, binding activity to receptors and ion channels was assessed by competition in radiolabeled ligand binding assays. The enzyme assays used a range of assay technologies depending on the enzyme class and activity, including radiometric and colorimetric assays. Information on specific assays can be found at http://www.cerep.fr/cerep/users/ pages/catalog/profiles/catalog.asp.

BioMAP Assays. The BioMAP assays (Supplemental Table 1) were performed at BioSeek (San Francisco, CA) with standardized protocols and methods described in recent publications (Kunkel et al., 2004a,b; Berg et al., 2010). Seletalisib and UCB1370037 were supplied on dry ice as a $1 \mathrm{mM}$ solution in DMSO and tested in a concentration response (seletalisib) or at a single concentration of $1 \mu \mathrm{M}$ (UCB1370037) to explore the effects of PI3K $\delta$-specific inhibition compared with complete inhibition of class I PI3K signaling. In addition, seletalisib was tested in the BioMAP BT cell system at concentrations of 1000, 100, 10, and $1 \mathrm{nM}$, and UCB1370037 at $1000 \mathrm{nM}$. An activity profile was generated on the basis of the effect of the compounds on the levels of cellular readouts, including cytokines, growth factors, adhesion molecules, and proliferation endpoints. Activity was considered significant when it fell outside the 99\% confidence interval (CI) calculated for the log ratio for each assay and endpoint.

Anti-IgM-Mediated Ramos Phosphorylated AKT Assay. Ramos cells (LGC Standards, Teddington, UK) were plated at $1 \times 10^{5}$ cells/well in serum-free RPMI 1640 (Life Technologies) in a 96-well plate to which serially diluted seletalisib was added. Anti-IgM (goat anti-human F(ab)2 IgM; Jackson ImmunoResearch Laboratories, West Grove, PA) in serum-free RPMI 1640 was added to all wells, with the exception of the negative control wells, at a final concentration of $20 \mu \mathrm{g} / \mathrm{ml}$. The plate was incubated $\left(10\right.$ minutes, $37^{\circ} \mathrm{C}$ with shaking), chilled on ice, and the cells pelleted by centrifugation. Cellular phosphorylated protein kinase B (AKT) was detected following the Meso Scale Diagnostics (MSD) pAKT assay protocol (Rockville, MD). Briefly, the cell pellet was lysed (30 minutes) in MSD lysis buffer then stored at $-80^{\circ} \mathrm{C}$ overnight. The lysate was thawed, transferred to the MSD assay plate, and incubated (room temperature, 1 hour). Following washing, the plate was incubated with detection antibody, washed, and read on an MSD plate reader.

fMLP- and PMA-Activated Human Neutrophil Assays. The enriched neutrophil fraction from human blood was prepared from granulocytes using Ficoll-Paque (GE Healthcare, Little Chalfont, UK). Separation followed by red blood cell lysis (with ammonium chloride) of the granulocyte/erythrocyte pellet. Granulocytes were incubated $\left(37^{\circ} \mathrm{C}, 30\right.$ minutes) with diluted seletalisib and further diluted in phosphate-buffered saline (PBS) supplemented as follows: $0.8 \mu \mathrm{g} / \mathrm{ml}$ dihydrocytochalasin B (Sigma-Aldrich), $0.5 \mathrm{IU} / \mathrm{ml}$ horseradish peroxidase type IV, $1 \mathrm{mM}$ sodium azide (Sigma-Aldrich), and $25 \mu \mathrm{M}$ Amplex Red (Invitrogen/Thermo Fisher Scientific) containing either fMLP $(20 \mathrm{nM})$ or PMA $(2 \mathrm{nM})$. Following incubation at $37^{\circ} \mathrm{C}$ for a further 30 minutes, fluorescence intensity was measured using a Synergy 2 plate reader (Biotek, Swindon, UK) with a 535-nm excitation filter and a $580-\mathrm{nm}$ emission filter. Percent inhibition was calculated on the basis of the minimum signal generated in the absence of stimulus and the maximum signal generated in the presence of fMLP or PMA.

T-Cell Activation Assay. Section 3.07 PBMCs were prepared from human donor blood using Leucosep tubes (Greiner Bio One, Stonehouse, UK) according to the manufacturer instructions. Briefly, blood diluted 1:1 (v/v) with RPMI 1640 was added to 50-ml Leucosep 
tubes and centrifuged (room temperature, 1000g, 10 minutes, no brake). The cells were washed with RPMI 1640, spun (250g, 10 minutes), and resuspended in RPMI 1640 [containing L-glutamine $5 \mathrm{mM}$ and $10 \%$ fetal bovine serum (FBS)]. Black clear-bottomed plates (Corning Costar, Corning, NY) were coated with $5 \mu \mathrm{g} / \mathrm{ml}$ mouse antihuman CD3 (UCHT1; R\&D Systems, Abingdon, UK) in PBS (Life Technologies), incubated overnight at $4^{\circ} \mathrm{C}$, and then washed three times in PBS. PBMCs were added to the anti-CD3-coated plates along with dilutions of seletalisib made in RPMI 1640. The plates were incubated ( 48 hours, $37^{\circ} \mathrm{C}, 5 \% \mathrm{CO}_{2}$ ) and centrifuged ( $300 \mathrm{~g}, 5$ minutes) before $25 \mu \mathrm{l}$ of supernatant was removed for cytokine analysis using the MSD cytokine multiplex assay (IFN- $\gamma$, IL-17, TNF- $\alpha$; Meso Scale Diagnostics), performed according to the manufacturer. Rat PBMCs were prepared from lithium-heparinized whole blood from healthy Wistar Han male rats (Harlan Laboratories, Indianapolis, IN) using Lympholyte-mammal cell separation media (VH Bio, Gateshead, UK). Briefly, $9 \mathrm{ml}$ blood diluted 1:2 (v/v) with PBS was added to $12 \mathrm{ml}$ Lympholyte-mammal cell separation media in Universal tubes and centrifuged (room temperature, 800g, 20 minutes, no break). The cells were washed with PBS, spun (1200 rpm, 4 minutes), and resuspended in assay media (RPMI 1640 containing L-glutamine $2 \mathrm{mM}, 10 \% \mathrm{FBS}, 50 \mathrm{IU} / \mathrm{ml}$ penicillin, $50 \mu \mathrm{g} / \mathrm{ml}$ streptomycin, and $0.5 \mathrm{M}$ 2-mercaptoethanol). U-bottomed tissue culture plates (Corning Costar) coated with $1 \mu \mathrm{g} / \mathrm{ml}$ mouse anti-rat CD3 (G4.18) in PBS, were incubated overnight at $4^{\circ} \mathrm{C}$, and then washed once in assay media. PBMC were added to the anti-CD3-coated plates along with dilutions of seletalisib made in RPMI 1640 . The plates were incubated (48 hours, $37^{\circ} \mathrm{C}, 5 \% \mathrm{CO}_{2}$ ) and centrifuged (300g, 5 minutes) before supernatant was removed for rat TNF- $\alpha$ detection using the R\&D Systems DuoSet antibodies (dy510) and MSD plates, according to the manufacturer's instructions.

House Dust Mite Assay. PBMCs were prepared (as detailed above) from blood drawn from human donors allergic to house dust mite (HDM). PBMCs $\left(2-4 \times 10^{5}\right.$ cells $)$ were plated in a 96 -well round-bottomed plate to which prediluted seletalisib and HDM extract (Dermatophagoides pteronyssinus; Greer Laboratories, Lenoir, NC) at $100 \mu \mathrm{g} / \mathrm{ml}$ was added (to give a final concentration of $25 \mu \mathrm{g} / \mathrm{m}$ ). The plates were incubated ( 6 days, $37^{\circ} \mathrm{C}, 5 \% \mathrm{CO}_{2}$ ) and then centrifuged ( $300 \mathrm{~g}, 5$ minutes). The supernatant was harvested (50 $\mu \mathrm{l}$ each) and IL-5 (Human IL-5 ELISA Assay Kit; R\&D Systems) and IL-13 enzyme-linked immunosorbent assays (ELISA) (Human IL-13 ELISA Assay Kit; Life Technologies) were performed according to manufacturer instructions. Percent inhibition was calculated on the basis of the minimum signal generated in the absence of HDM and the maximum signal generated in the presence of HDM.

B-Cell Proliferation. B-cells were isolated from PBMCs, cryopreserved tonsil suspensions, or buffy coats that had undergone plateletpheresis by CD19-selection (B-cell Isolation Kit II; Miltenyi Biotec, Bisley, UK). Purity of $\mathrm{CD} 9^{+}$cells was determined to be $\geq 98 \%$ by staining with anti-CD19-APC and anti-CD45-FITC antibodies (BD Biosciences, Oxford, UK) and analyzing by flow cytometry. Non-CD19 cells, collected as the APC fraction, were counted, treated with mitomycin $\mathrm{C}\left(25 \mu \mathrm{g} / \mathrm{ml}, 40\right.$ minutes, $\left.37^{\circ} \mathrm{C}\right)$, centrifuged (300g, 5 minutes), and washed twice with RPMI 1640 (containing, L-glutamine $5 \mathrm{mM}$ and $10 \% \mathrm{FBS}$ ) to remove all traces of mitomycin $\mathrm{C}$. The cells were then resuspended in RPMI 1640 .

CD19 ${ }^{+}$cells were washed with PBS and resuspended in PBS at room temperature. The same volume of CFSE (Life Technologies) solution was added to the cells (final concentration of CFSE: $0.25 \mu \mathrm{M}$ ). The $\mathrm{CD} 19^{+}$cells were incubated (room temperature, 10 minutes, dark) before at least $10 \mathrm{ml}$ of RPMI 1640 with $20 \%$ fetal calf serum was added to inactivate the CFSE. The cells were centrifuged (300g, 5 minutes), the supernatant discarded, and the PBMCs washed (RPMI 1640, L-glutamine $5 \mathrm{mM}, 10 \% \mathrm{FBS}$ ). The centrifugation and washing of the PBMCs was repeated, and the cells resuspended in RPMI 1640.
The $\mathrm{CD} 19^{+}$cells were plated in a 96 -well U-bottom plate to which the APCs and prediluted seletalisib were added. The plates were incubated $\left(1\right.$ hour, $37^{\circ} \mathrm{C}, 5 \% \mathrm{CO}_{2}$ ) and stimulation media was added so that the final culture media was RPMI 1640, L-glutamine $5 \mathrm{mM}, 10 \%$ FBS, $5 \mu \mathrm{g} / \mathrm{ml}$ anti-IgM, F(ab)2 (Jackson ImmunoResearch Laboratories), $20 \mathrm{ng} / \mathrm{ml} \mathrm{IL-2,} \mathrm{and} 20 \mathrm{ng} / \mathrm{ml}$ IL-10 (R\&D Systems).

The cells were incubated ( 6 days, $37^{\circ} \mathrm{C}, 5 \% \mathrm{CO}_{2}$ ) and then analyzed by flow cytometry. CFSE was detected in the FL1 channel and B-cells were detected using APC-labeled CD19 antibody. Dilution of the CFSE signal in gated $\mathrm{CD} 19^{+}$cells was detected and used as a measure of proliferation. The effect of seletalisib was expressed as percentage inhibition of the maximal response (DMSO-stimulated control) compared with the unstimulated minimal response.

CpG-Induced IL-6 and IL-10 Cytokine Secretion by Purified B-Cells. CD19 ${ }^{+}$B-cells were isolated from PBMCs by negative selection, as described above, and resuspended in RPMI 1640 (containing L-glutamine $5 \mathrm{mM}$ and $10 \% \mathrm{FBS}$ ). In a 96 -well U-bottom plate, $1 \times 10^{5} \mathrm{CD}^{+} 9^{+}$cells were incubated with serially diluted seletalisib ( 1 hour, $37^{\circ} \mathrm{C}, 5 \% \mathrm{CO}_{2}$ ) prior to stimulation with $2.5 \mu \mathrm{g} / \mathrm{ml} \mathrm{CpG} \mathrm{oligodeoxynucleotides} \mathrm{(ODN} \mathrm{2006;} \mathrm{Invivogen,} \mathrm{San}$ Diego, CA). After 48 hours, culture supernatants were harvested and IL- 6 and IL-10 levels were determined by human ELISA assays (R\&D Systems). The effect of seletalisib was expressed as percentage inhibition of the maximal response (DMSO, CpG-stimulated control) compared with the unstimulated control.

Anti-IgM-Mediated CD69 B-Cell Activation Assay. Whole blood was collected in sodium heparin vacutainers from human donors. Whole blood aliquots $(100 \mu \mathrm{l})$ were incubated with antihuman IgM ( $50 \mu \mathrm{g} / \mathrm{ml}$; Stratech, Newmarket, UK) to activate B-cells or PBS in a 96-well plate in assay medium (ratio of whole blood to media, 90\%) consisting of RPMI 1640 with $10 \%$ human AB serum, $50 \mathrm{IU} / \mathrm{ml}$ penicillin, $50 \mu \mathrm{g} / \mathrm{ml}$ streptomycin, and $2 \mathrm{mM}$ glutamine. The anti-human IgM-stimulated samples were further incubated for 20 hours at $37^{\circ} \mathrm{C}$ with PBS, DMSO or fixed concentrations (10-12 at $0.5 \mathrm{log}$ unit increments) of seletalisib over the concentration range of $0.03 \mathrm{nM}$ to $10 \mu \mathrm{M}$. For detection of the level of B-cell activation, samples were stained for CD19 (1:300 dilution of anti-human CD19 APC; BD Biosciences) and CD69 (1:300 dilution of anti-human CD69 phycoerythrin (PE); BD Biosciences) and/or the corresponding isotype control antibodies (IgGk1 Isotype Control PE; BD Biosciences) using a 30 -minute incubation at $37^{\circ} \mathrm{C}$. The isotype control antibodies were used to determine the level of background staining. Red blood cells were then lysed using FACS Lysing Solution (BD Biosciences) and the samples were centrifuged at $600 \mathrm{~g}$ for 6 minutes and the pellets were resuspended in $100 \mu \mathrm{l}$ of fluorescence-activated cell sorting (FACS) buffer prior to analysis. The mean fluorescence intensity of CD69 staining on $\mathrm{CD} 19^{+}$cells was determined on BD FACSCanto (BD Biosciences) and data analysis was performed using Flowjo Software.

Anti-IgE-Mediated Basophil Degranulation Assay. One hundred microliters of whole blood drawn from human donors was added to a 96 -well plate at $37^{\circ} \mathrm{C}$ for 1 hour. Seletalisib prepared in basophil stimulation buffer (BSB; BD Biosciences) was added to the blood and incubated $\left(37^{\circ} \mathrm{C}, 45\right.$ minutes). Degranulation was stimulated with the addition of $2 \mu \mathrm{g} / \mathrm{ml}$ anti-IgE (Dako, Glostrup, Denmark) diluted in $\mathrm{BSB}$ to the plate. The plate was incubated $\left(37^{\circ} \mathrm{C}, 12\right.$ minutes $)$ and the degranulation stopped by placing the plate on ice (10 minutes). Basophil activation was detected using flow cytometry and an antibody cocktail (CD123/HLA-DR/CD63; BD Biosciences) or single stains (human blood: CD123 clone 9F5; BD Biosciences) for compensation controls. Antibodies were added, the blood mixed, and the 96 -well plates then incubated on ice ( 45 minutes, dark). The whole blood samples were lysed with FACS Lysing Solution (BD Biosciences) and centrifuged (1000g, 5 minutes). Supernatant was aspirated with the exception of the last 300-400 $\mu \mathrm{l}$ that contained cells, and samples were analyzed on a BD FACSCanto flow cytometer (BD Biosciences). At least 500 basophil events were acquired per sample. Cells with a side scatter low $\left(\mathrm{SSC}^{\mathrm{lo}}\right), \mathrm{CD}_{123^{+}}$phenotype were gated. Basophils 
were identified as the $\mathrm{SSC}^{\mathrm{lo}}, \mathrm{CD} 123^{+} \mathrm{HLA}^{-\mathrm{DR}^{-}}$population. The cells that were $\mathrm{CD}_{123}{ }^{+}$and HLA-DR ${ }^{-}$were further analyzed for their CD63 cell surface expression as a measure of degranulation. The BSB control was used to set the baseline CD63 level and the anti-IgE control was used to establish the maximal response.

Anti-CD3 Antibody-Induced IL-2 Release in the Lewis Rat. Adult Lewis rats (male, 6-8 weeks of age) were used in accordance with the Animals (Scientific Procedures) Act 1986 and were purchased from Charles River (Margate, UK). Animals were kept under a light/dark cycle of 12/12 hours and had access to food and water ad libitum.

Rats were dosed with seletalisib $(0.1-10 \mathrm{mg} / \mathrm{kg}$ in $500 \mu \mathrm{l}$ volume) or vehicle via oral gavage $(75 \mathrm{~mm}, 16$-guage curved stainless steel cannula; Vet-Tech Solutions, Cheshire, UK) 30 minutes prior to intravenous administration ( $16 \mathrm{~mm} 26$-gauge needle; Becton Dickinson Medical, Oxford, UK) of anti-CD3 antibody (100 $\mu \mathrm{g} / \mathrm{kg}$; BD Biosciences) administered in a $200-\mu \mathrm{l}$ dose volume. The vehicle was methylcellulose (0.5\%, $400 \mathrm{cps}$; Sigma Aldrich, Gillingham, Dorset, UK) or saline (Polyfusor; Fresenius Kabi Ltd, Runcorn, UK) for oral and intravenous administration, respectively. To assess basal IL-2 levels, a group of animals received vehicle both orally and intravenously. Animals were anesthetized with isoflurane (Henry Schein Animal Health, Dumfries, UK) for the intravenous administration. At 90 minutes post-anti-CD3 antibody, the rats were anesthetized and blood was removed by terminal cardiac puncture into EDTA or heparin-coated tubes (Multivette $600 \mu \mathrm{l}$ lithium heparin or Multivette $600 \mu \mathrm{l}$ K3 EDTA; Sarstedt AG \& Co., Nümbrecht, Germany) and then killed by cervical dislocation. Two samples were prepared from the blood, enabling pharmacokinetic analysis of seletalisib levels and IL-2 levels.

IL-2 levels were measured from plasma using the Rat IL-2 Quantikine ELISA Kit (R\&D Systems) per manufacturer instructions and with the plasma samples being diluted 1:2 prior to analysis. Dunnett's multiple comparison tests (GraphPad Prism version 6.01) were used to test for statistical difference between the drug treatment groups and the positive control group.

For the bioanalysis of seletalisib, blood samples were diluted 50:50 with water and measured against calibration standard prepared in matrix akin to study samples. Samples and calibration standards were precipitated in acetonitrile containing internal standard $(100 \mathrm{ng} / \mathrm{ml})$, mixed, and centrifuged at $4000 \mathrm{rpm}$ for 10 minutes. The supernatant was reconstituted in $20 \%$ acetonitrile and injected into a liquid chromatography coupled with tandem mass spectrometry (LC-MS/MS) system. LC-MS/MS analysis was carried out by Agilent 1100 series binary pump (Agilent Technologies, Stockport, UK) coupled to electrospray ionization-triple quadruple mass spectrometer (Micromass Quattro Utima; Waters Ltd, Elstree, UK). The extracted sample was injected by CTC Analytics HTS Pal autosampler (Presearch, Hitchin, UK) onto a reversed-phase high-performance liquid chromatography column (Phenomenex Luna 5- $\mu \mathrm{m}$ C18 100Å LC column, $50 \times 2.0 \mathrm{~mm}$; Phenomenex, Macclesfield, UK) maintained at $40^{\circ} \mathrm{C}$. A linear gradient of 5-95\% acetonitrile in $0.1 \%$ formic acid was applied for 1.5 minutes at a flow rate of $1 \mathrm{ml} / \mathrm{min}$ with a split ratio of 5:1 to the mass spectrometer. The mass spectrometer was set up to run multiple reaction monitoring analysis to detect multiple transitions at a dwell time of 100 milliseconds per transition.

TABLE 1

Seletalisib is a potent and selective inhibitor of PI3K $\delta$

\begin{tabular}{lcc}
\hline \multirow{2}{*}{ PI3K Isoform $(n)$} & \multicolumn{2}{c}{$\mathrm{IC}_{50}$ (Fold Selectivity for PI3K $\left.\delta\right)$} \\
\cline { 2 - 3 } & Seletalisib & $\mathrm{UCB} 1370037$ \\
\hline & $n M$ & $n M$ \\
$\mathrm{PI} 3 \mathrm{~K} \delta(7-10)$ & $12(-)$ & $2.7(-)$ \\
$\mathrm{PI} 3 \mathrm{~K}(4-7)$ & $282(24 \mathrm{x})$ & $37(14 \mathrm{x})$ \\
$\operatorname{PI} 3 \mathrm{~K} \beta(3-7)$ & $2129(177 \mathrm{x})$ & $78(29 \mathrm{x})$ \\
$\operatorname{PI} 3 \mathrm{~K} \alpha(5-7)$ & $3638(303 \mathrm{x})$ & $3.6(1 \mathrm{x})$ \\
\hline
\end{tabular}

\section{Results}

\section{Seletalisib Is a Potent, Selective, and ATP-Competitive Inhibitor of PI3K $\delta$}

FRET-based protein kinase activity assays showed that seletalisib is a potent and selective inhibitor of the PI3K $\delta$ isoform. The potency and selectivity of seletalisib against the four PI3K isoforms generated are shown in Table 1. Seletalisib had an $\mathrm{IC}_{50}$ value for PI3K $\delta$ of $12 \mathrm{nM}$ [geometric mean, 95\% CI, 8.4-17.1 $(n=10)$ ] and showed significant selectivity to PI3K $\delta$ with respect to the other class I PI3K isoforms (between 24- and 303-fold). The pan-PI3K inhibitor UCB1370037 showed particularly poor selectivity against the ubiquitously expressed PI3K $\alpha$ isoform. Increasing the concentration of ATP in the PI3K $\delta$ TR-FRET assay resulted in a reduction in the potency of seletalisib, indicating that its inhibitory activity is competitive with respect to ATP (Fig. 2).

In vitro receptor binding and enzyme assays across a broad range of target classes showed that seletalisib is selective for PI3K $\delta$ (Supplemental Table 2). From 239 kinases screened, seletalisib at a concentration of $10 \mu \mathrm{M}$ showed no inhibitory activity greater than 47\% (MAP4K4) against non-PI3K kinase enzymes (Supplemental Table 2A). Against nonkinase enzymes, seletalisib showed weak activities against phosphodiesterase (PDE)3A, PDE2A1, and PDE4D2, with inhibition varying between 32 and $74 \%$ at $10 \mu \mathrm{M}$ (Supplemental Table 2B). When screened at a concentration of $10 \mu \mathrm{M}$ against 55 receptors and ion channels, the highest inhibitory activity of seletalisib observed was 20\% (Supplemental Table 2C). One receptor, neuropeptide Y receptor (Y1) showed 54\% activation. In vitro receptor binding and enzyme assays across a broad range of target classes showed that seletalisib is selective for PI3K $\delta$.

Seletalisib Potently Inhibits Signaling through the B-Cell Receptor. PI3K $\delta$ has been shown to be a requirement for signaling downstream of the BCR (Al-Alwan et al., 2007). Activation of this receptor results in $\mathrm{PI} 3 \mathrm{~K} \delta$-dependent phosphorylation of AKT at serine 473 (Bilancio et al., 2006). The ability of seletalisib to inhibit AKT phosphorylation on B-cell ligation with anti-IgM crosslinking was determined in Ramos cells (a human B-cell line derived from a patient with Burkitt's

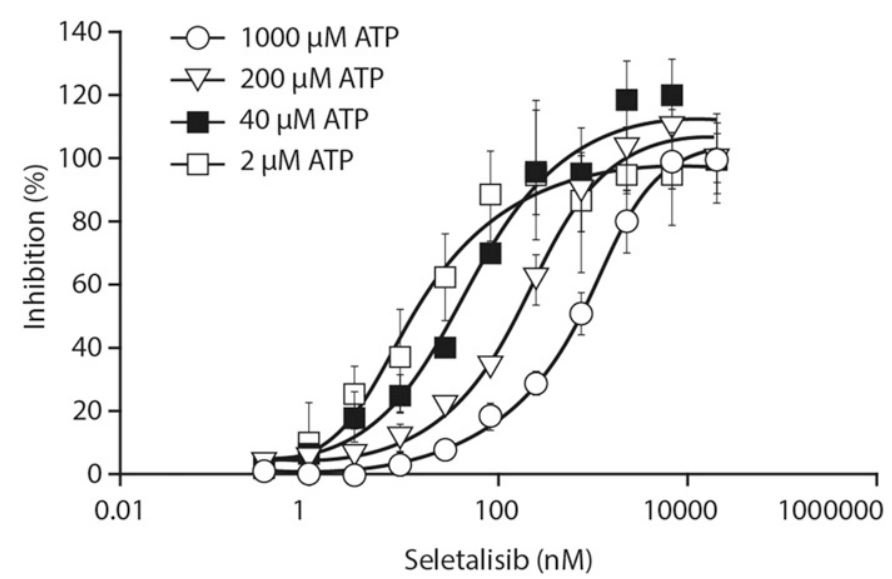

Fig. 2. Seletalisib is a selective, ATP-competitive PI3K $\delta$ inhibitor. Concentration response curves of seletalisib in the PI3K $\delta$ competitive TR-FRET assay at different concentrations of ATP $(2,40,200$, and $1000 \mu \mathrm{M})$. Data are mean \pm S.D. $(n=3)$. 

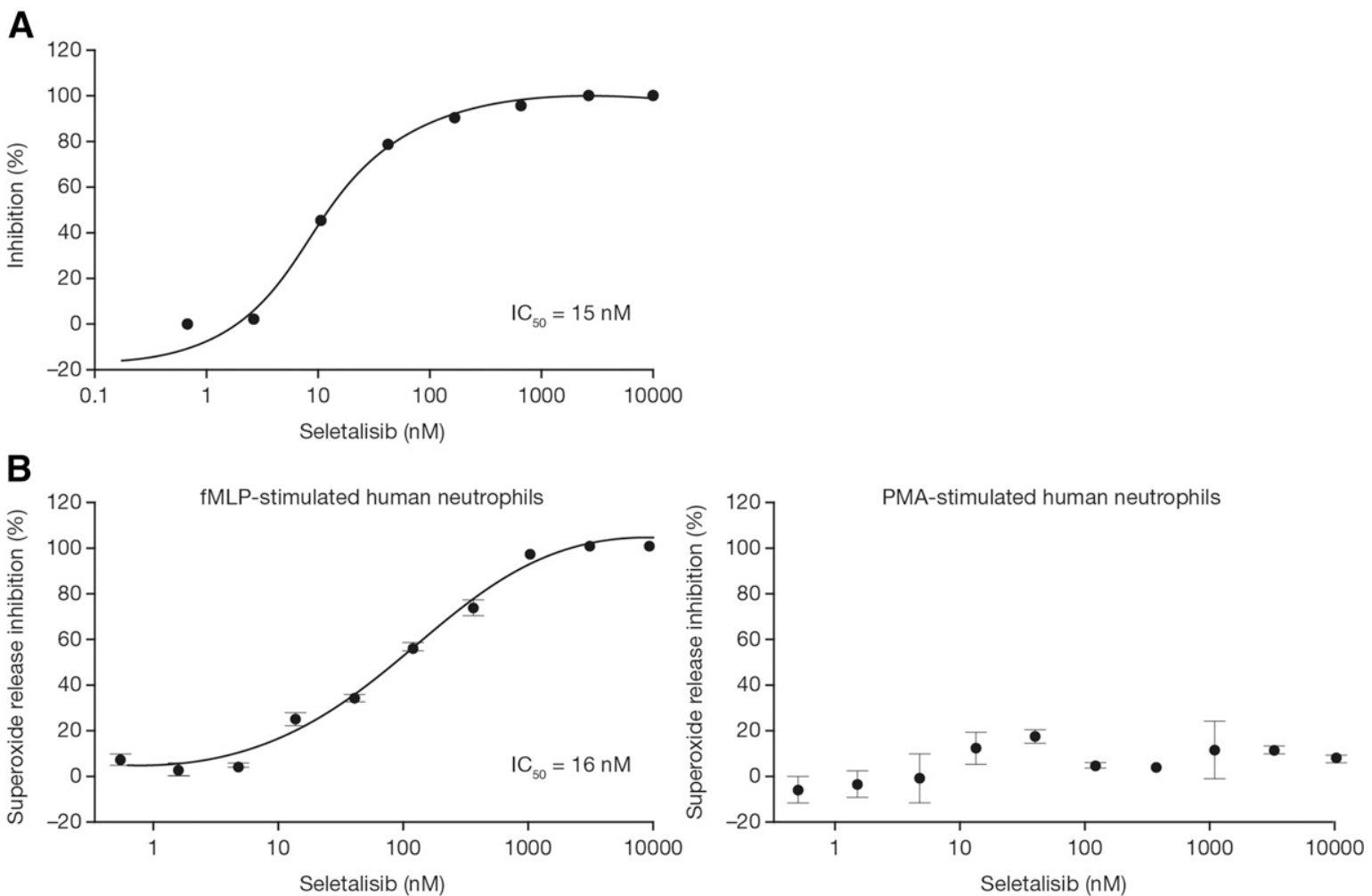

Fig. 3. Seletalisib shows potent and selective cellular inhibition of PI3K $\delta$ signaling. (A) Representative graph of the inhibition by seletalisib of anti-IgMmediated phosphorylated AKT assay in the Ramos B-cell line. Serially diluted seletalisib and goat anti-human F(ab)2 IgM in serum-free RPMI 1640 were added to Ramos cells plated in serum-free RPMI 1640. The plate was incubated for 10 minutes, chilled on ice, and the cells pelleted by centrifugation. Cellular phosphorylated AKT was detected by MSD assay. Data are mean \pm S.D. $(n=6)$. (B) Representative graphs showing seletalisib inhibition of superoxide release stimulated by fMLP- or PMA-stimulated human neutrophils. Granulocytes prepared from human blood were incubated with diluted seletalisib and further diluted in PBS supplemented with a superoxide detection substrate mix. Cells were incubated for 30 minutes at $37^{\circ} \mathrm{C}$ and fluorescence intensity was measured using a plate reader. Data are mean \pm S.D. $(n=20)$. (C) BioMAP profiling of seletalisib (blue line) and the panPI3K inhibitor UCB1370037 (red line), tested at $1000 \mathrm{nM}$ across a range of primary human cell functional assays that assess their effects on the levels of cellular readouts, including cytokines, growth factors, adhesion molecules, cytotoxicity (sulforhodamine B), and proliferation (left). An activity profile was also generated on the basis of the effect of seletalisib at 1000,100,10, and $1 \mathrm{nM}$ (red, orange, yellow, and green lines, respectively) on readouts in the BT cell system (right). 3C and 4C, venular endothelial cells; 4H and SAg, PBMCs + venular endothelial cells; BE3C, bronchial epithelial cells; CASM3C, coronary artery smooth muscle cells; HDF3CGF, dermal fibroblasts; MyoF, lung fibroblasts; /Mphg, venular endothelial cells + M1 macrophages; BT, B cells + PBMCs. Further details on the cell systems used in the panels are in Supplemental Table 1.

lymphoma). Seletalisib potently inhibited the phosphorylation of AKT following anti-IgM stimulation of the BCR on Ramos cells with an $\mathrm{IC}_{50}$ of $15 \mathrm{nM}$ [geometric mean, $95 \% \mathrm{CI}$, 9.3-23.5 $(n=6)$ ] (Fig. 3A).

Seletalisib Inhibits flMIP-Stimulated Human Neutrophil Superoxide Release Assay. PI3K $\delta$ has been shown to be a requirement for superoxide generation by neutrophils, cells of the innate immune system, stimulated with the bacterial peptide ligand fMLP (Condliffe et al., 2005). Generation of superoxide in human neutrophils stimulated with an alternative ligand, PMA, is signaled through protein kinase $\mathrm{C}$ and is not dependent on PI3K $\delta$. When the activity of seletalisib was tested in fMLP-stimulated and in PMA-stimulated human neutrophil superoxide release assays, the fMLPstimulated superoxide was inhibited by seletalisib with an $\mathrm{IC}_{50}$ of $16 \mathrm{nM}$ (Fig. 3B; geometric mean, 95\% CI, 11-24 [ $n=$ $20]$ ). The PMA-activated superoxide release assay was not inhibited by seletalisib.

BioMAP Profiling Illustrates the Selective PI3K $\delta$ Inhibition by Seletalisib and Characterizes Specific Effects on B- and T-Cell Activation. The BioMAP profile for seletalisib is shown and compared with a pan-PI3K inhibitor, UCB1370037 (Fig. 3C and Supplemental Table 1). Seletalisib showed little or no activity in the PBMC cytotoxicity assays (SRB) but was shown to have selective effects on T-cell-dependent B-cell activation readouts, including B-cell proliferation and antibody class-switching. Furthermore, seletalisib inhibited the release of cytokines involved in T-cell activation responses through TCR stimulation. Seletalisib was shown to have a comparatively selective BioMAP profile with activities confined to the SAg cell system (PBMC + endothelial cells stimulated via the TCR) and, most profoundly, in the BT coculture cell system [B-cells + PBMC stimulated with anti-IgM + staphylococcal enterotoxin B (SEB) + toxic shock syndrome toxin (TSST)]. In the BT cell system, seletalisib was shown to strongly inhibit B-cell proliferation and cytokine production (IL-2, TNF- $\alpha$, IL17A, and IL17F) and also inhibit the production of secreted IgG. In addition, seletalisib was also shown to inhibit E-selectin, IL-8, and proliferation responses in the BioMap SAg cell system. Seletalisib had a selective effect on these specific immune cell BioMAP systems and had no significant effects on other systems. Conversely, in addition to effects on immune cell systems, UCB1370037 also modulated responses in systems containing endothelial cells (3C and 4H), epithelial cells (BE3C), smooth muscle cells (CASM3C), fibroblasts (HDF3CGF), and myofibroblasts $(\mathrm{MyoF})$. 


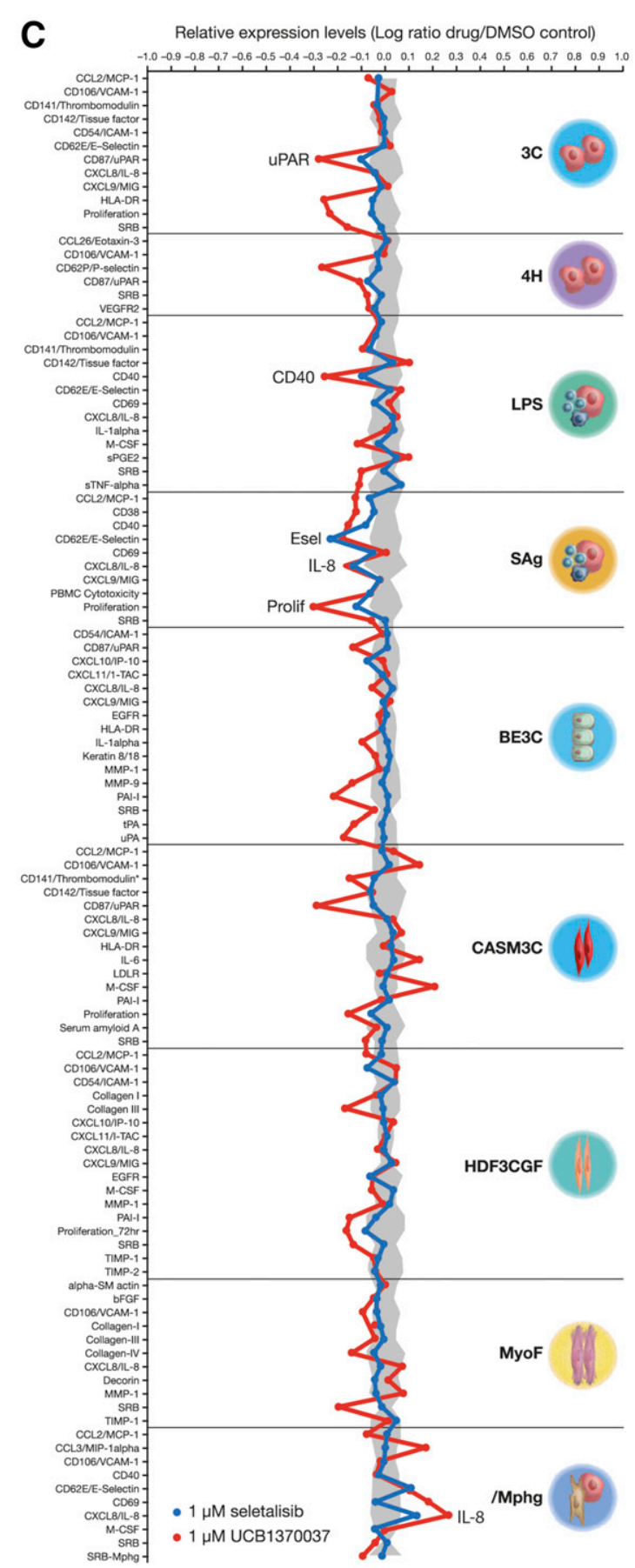

\section{Seletalisib Shows Anti-Inflammatory Activity in Cellular Assays of Adaptive Immunity}

Seletalisib Inhibits T-Cell Cytokine Production. PI3K $\delta$ activity is required for T-cell differentiation and function, as demonstrated in studies of genetic ablation of PI3K $\delta$ in mouse cells and PI3K $\delta$ inhibitors in human cells (Okkenhaug et al., 2006; Soond et al., 2010). The activity of seletalisib was characterized in primary T-cell assays. Secretion of inflammatory cytokines was measured 48 hours post-anti-CD3 stimulation of PBMCs in the presence and absence of seletalisib. The compound inhibited IFN $\gamma$, IL-17, and TNF- $\alpha$ secretion from PBMCs with $\mathrm{IC}_{50}$ values of 54,21 , and
Fig. 3. Continued.
$31 \mathrm{nM}$, respectively (5-6 donors; Fig. 4A). As seletalisib was to be assessed in an in vivo rat model, we wished to characterize the functional potency of seletalisib in a rat cellular assay similar to those established in human systems. Activation of isolated rat PBMCs with anti-CD3 resulted in the release of TNF- $\alpha$, which was inhibited by seletalisib with a potency of $22 \mathrm{nM}(n=2)$, similar to the potency of seletalisib in the equivalent anti-CD3-stimulated $\mathrm{TNF}-\alpha$ release from human PBMCs (31 nM). Seletalisib also inhibited HDMinduced IL-5 and IL-13 secretion from HDM-allergic human donor PBMCs (mean $\mathrm{IC}_{50}$ values of 15 and $2 \mathrm{nM}$, respectively, 2 donors; Fig. 4B). 
A
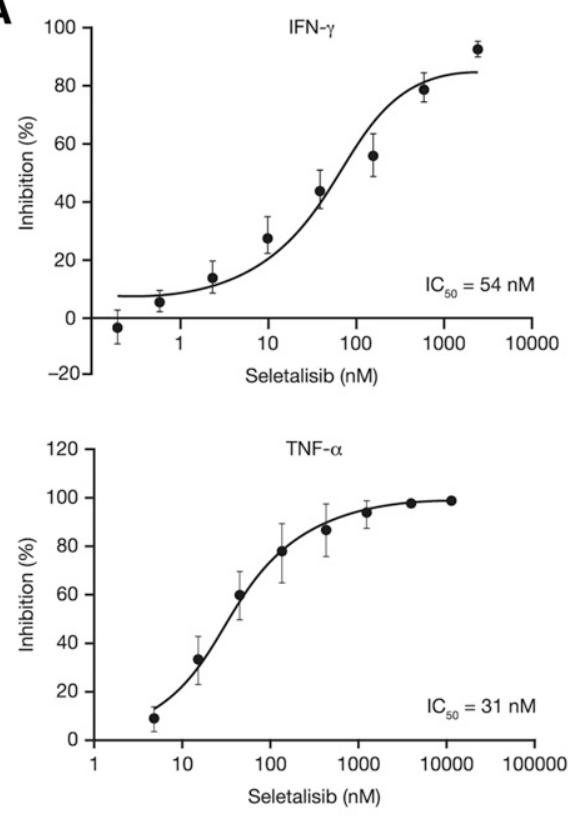

B

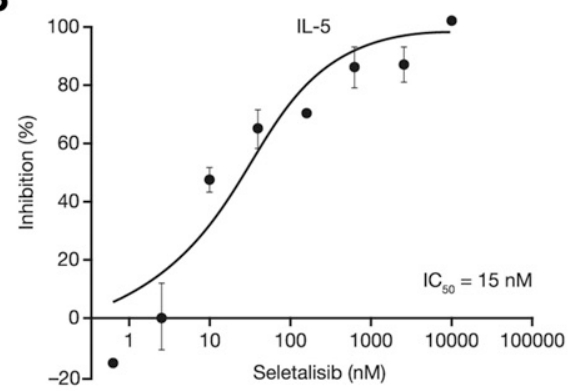

C
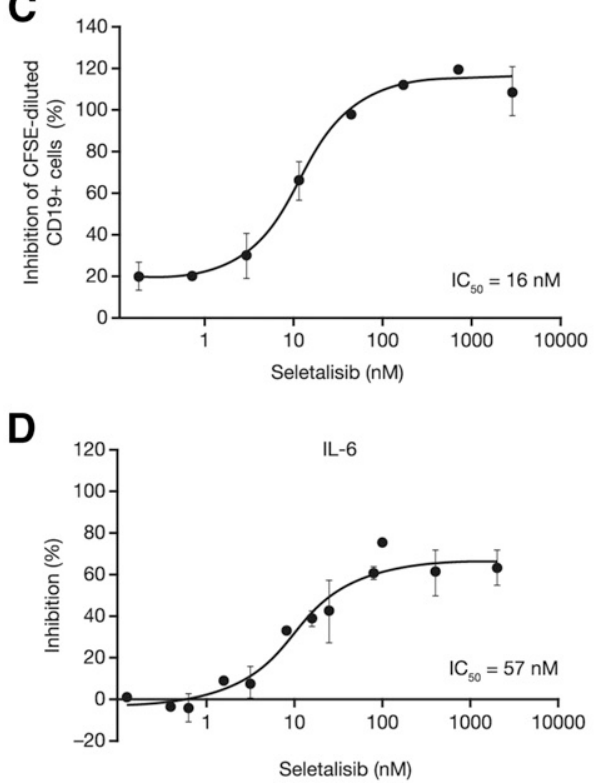
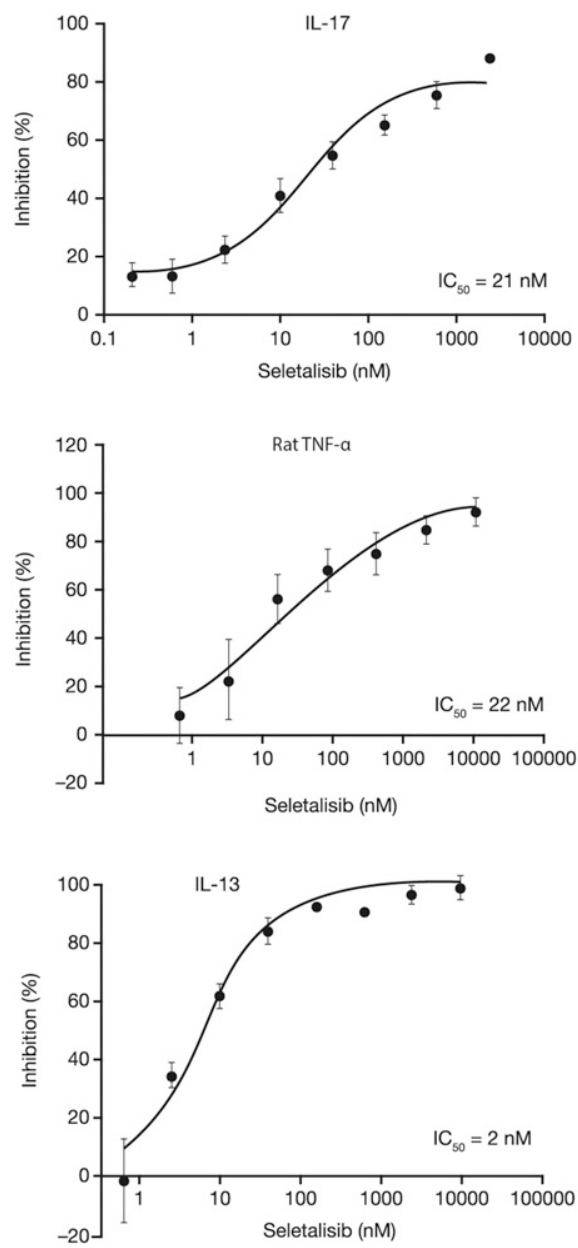

Fig. 4. Seletalisib shows anti-inflammatory activity in cellular assays of adaptive immunity. (A) Inhibition of plate-bound anti-CD3induced cytokine secretion from PBMCs by seletalisib. PBMCs were prepared with human donor blood and seletalisib added to anti-CD3-coated plates, which were incubated for 48 hours at $37^{\circ} \mathrm{C}$ before supernatant was removed for cytokine analysis. Data are mean \pm S.D. $(n=5-6$ donors $)$. Further, the potency of seletalisib in blocking TNF- $\alpha$ release from isolated rat PBMCs following stimulation by plate-bound antiCD3 for 48 hours at $37^{\circ} \mathrm{C}$ was determined. Data are mean \pm S.D. $(n=2)$. (B) Inhibition of HDM-induced IL-5 and IL-13 secretion from HDM-allergic human donor PBMCs by seletalisib. PBMCs were prepared using blood drawn from human donors allergic to HDM. PBMCs, prediluted seletalisib, and HDM extract were added to plates that were incubated for 6 days before supernatant was removed for IL-5 and IL-13 ELISA analysis. Data are mean \pm S.D. $(n=2$ donors $)$. (C) Effects of seletalisib on B-cell proliferation. B-cells were isolated from PBMCs by CD19 selection and stained with CFSE. B-cells were mixed with antigen presenting cells (non-CD19 ${ }^{+}$cells) and prediluted seletalisib. The plates were incubated for 1 hour at $37^{\circ} \mathrm{C}$ and stimulation media containing anti-IgM, IL-2, and IL-10 was added. Cells were incubated for 6 days at $37^{\circ} \mathrm{C}$ and analyzed by flow cytometry. CFSE was detected in the FL1 channel, and B-cells were detected using APC-labeled CD19 antibody. Dilution of the CFSE signal in gated CD19 ${ }^{+}$ cells was detected and used as a measure of proliferation ( $n=3$ donors). (D) Effects of seletalisib on B-cell cytokine release in human primary cell functional assay. CD19 ${ }^{+}$B-cells were isolated from PBMCs and incubated with serially diluted seletalisib prior to stimulation with CpG ODN 2006 for 48 hours at $37^{\circ} \mathrm{C}$. IL-6 and IL-10 levels in culture supernatants were determined by human ELISA assays ( $n=3-4$ donors).

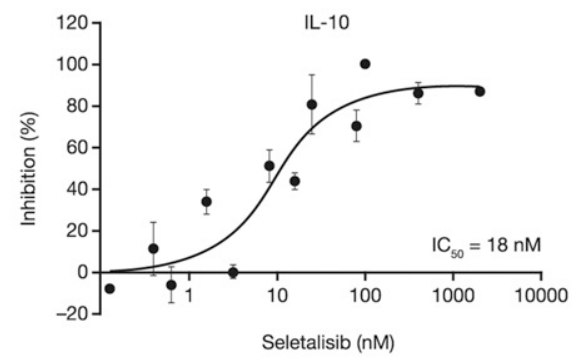

Seletalisib Inhibits B-Cell Function. The activity of seletalisib was assessed in a functional B-cell assay by stimulating human PBMCs with anti-IgM and measuring the proliferation of B-cells. In this system, seletalisib inhibited
B-cell proliferation ( $\mathrm{IC}_{50} 16 \mathrm{nM}$, range $10-19 \mathrm{nM}, n=3$ donors) (Fig. 4C). Furthermore, seletalisib inhibited IL-6 and IL-10 release in human B-cells stimulated with CpG ODN 2006, an agonist that signals selectively via TLR9 (Dil and Marshall, 
$2009)$, with $\mathrm{IC}_{50}$ values of $57 \mathrm{nM}(95 \% \mathrm{CI}, 33-101 \mathrm{nM}, n=4$ donors) and $18.1 \mathrm{nM}$ (95\% CI, 10-34 nM, $n=3$ donors), respectively (Fig. 4D).

\section{Seletalisib Shows Anti-Inflammatory Activity in Whole Blood Assays}

In addition to assays on isolated human cells, the activity of seletalisib was evaluated in a more physiologic environment, human whole blood. In whole blood activation assays, seletalisib inhibited anti-IgM-induced CD69 expression on B-cells in a concentration-dependent manner across five donors (Fig. $5 \mathrm{~A}$ ). An $\mathrm{IC}_{50}$ value of $57 \mathrm{nM}$ (geometric mean, 95\% CI, 22-143 $[n=5]$ ) was obtained.

Basophils are circulating granulocytes that play a role in allergic hypersensitivity reactions. FceR1/IgE-induced degranulation has been shown to be PI3K $\delta$ dependent and therefore provided a mechanistic readout of the activity of seletalisib (Ali et al., 2004, 2008). In a degranulation assay developed with human whole blood, seletalisib blocked antiIgE-triggered CD63 cell surface expression, a marker of
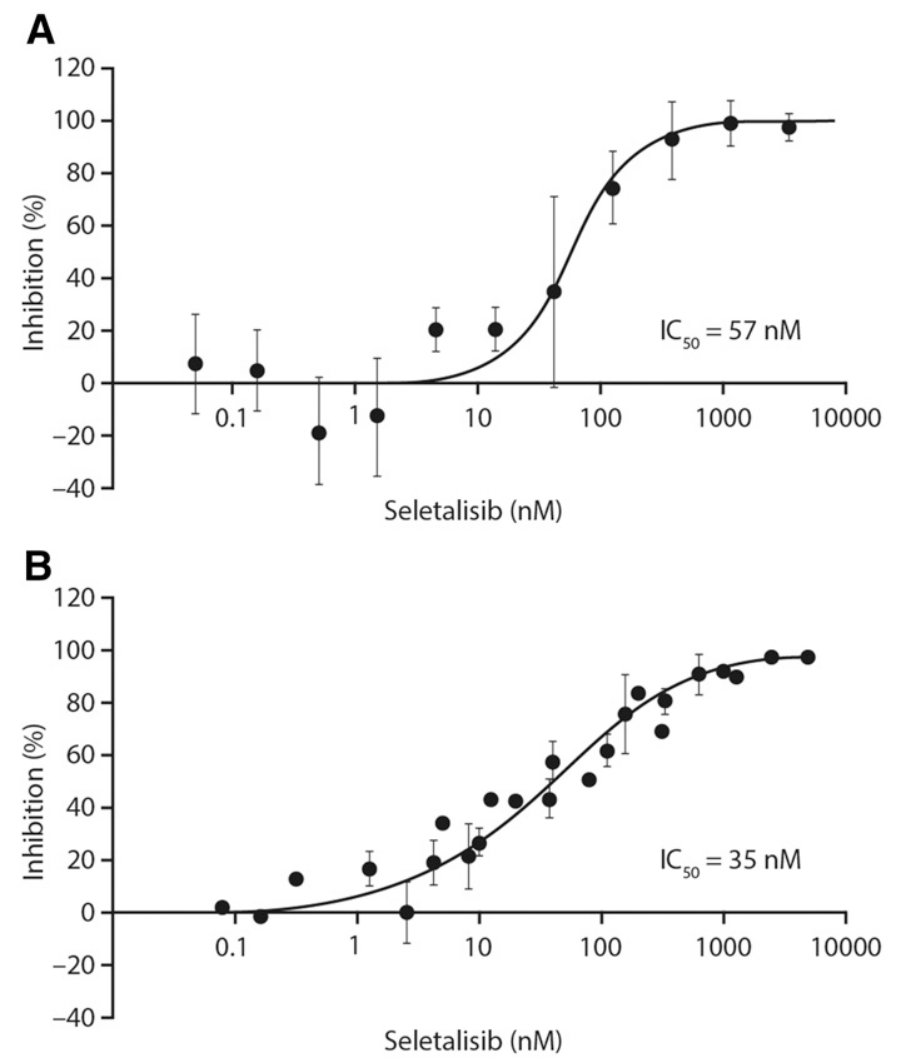

Fig. 5. Seletalisib shows potent activity in human whole blood assays. (A) Effects of seletalisib on anti-IgM-mediated CD69 expression on B-cells. Whole blood from human donors was incubated with anti-human IgM or PBS. Anti-human IgM-stimulated samples were incubated with PBS, DMSO, or seletalisib for 20 hours at $37^{\circ} \mathrm{C}$. Staining for CD19 and CD69 and/or the corresponding isotype control antibodies was used to detect B-cell activation by flow cytometry. Data are geometric mean \pm S.E. $(n=$ 5 donors). (B) Seletalisib inhibits basophil degranulation in healthy donor human blood. Seletalisib prepared in basophil stimulation buffer was added to plated whole blood and incubated. Degranulation was stimulated by adding anti-IgE. Basophil activation was detected by flow cytometry. Degranulation was measured by cell-surface CD63 expression on CD123 ${ }^{+}$ and HLA-DR ${ }^{-}$cells. Data are mean \pm S.D. $(n=3$ donors $)$. basophil degranulation. This was achieved with an $\mathrm{IC}_{50}$ of $35 \mathrm{nM}$ (geometric mean, 95\% CI, 27-45 [n=13]) (Fig. 5B).

\section{Seletalisib Shows In Vivo Activity in a Rodent Model of Cytokine Release following T-Cell Activation through TCR Stimulation}

Activation of T cells through TCR stimulation following anti-CD3 administration results in the release of cytokines, of which IL-2 is one of the earliest cytokines released. Seletalisib significantly inhibited IL-2 release following TCR stimulation in the rat. The inhibition was observed at all tested doses of seletalisib with almost complete inhibition reached at dose levels $\geq 1 \mathrm{mg} / \mathrm{kg}$. A representative experiment is shown in Fig. $6 \mathrm{~A}$. Analysis of the relationship between inhibition of IL-2 release and seletalisib blood concentration, using combined

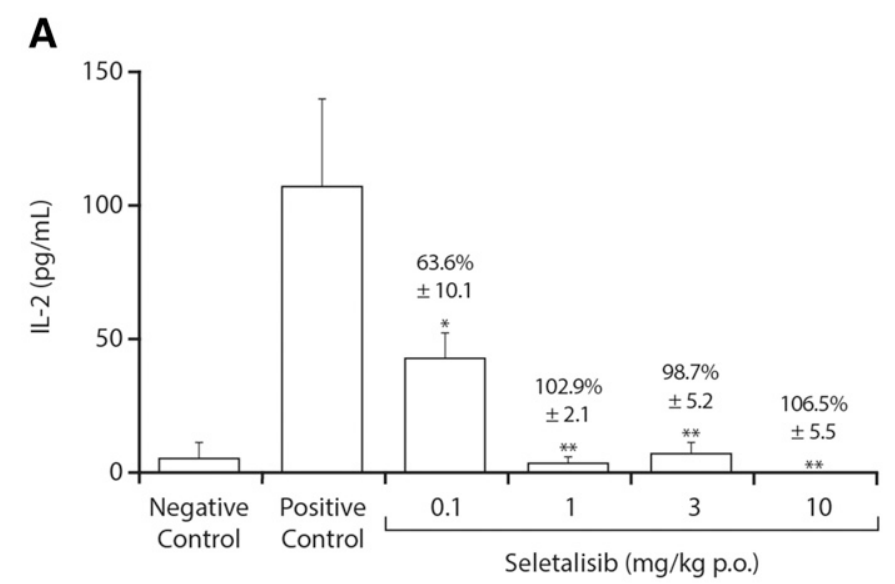

B

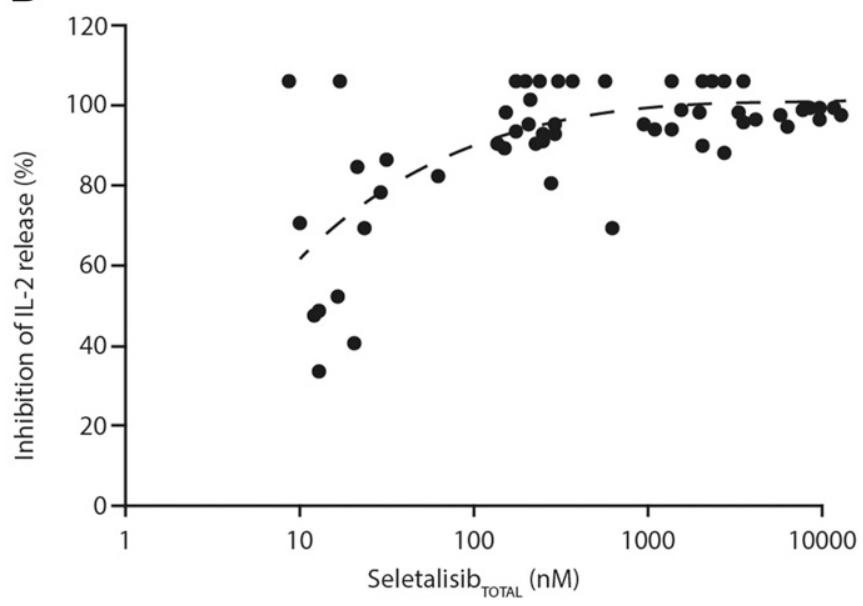

Fig. 6. Seletalisib is a potent inhibitor of IL-2 release in a rat model of inflammation (primary pharmacology model). (A) IL-2 levels in treatment groups from one representative experiment. Adult Lewis rats (male, 6-8 weeks of age) were dosed with oral seletalisib $(0.1-10 \mathrm{mg} / \mathrm{kg}) \mathrm{prior}$ to intravenous administration of anti-CD3 antibody. The vehicle was methylcellulose or saline for oral and intravenous administration, respectively. Basal IL-2 levels were determined in animals that received vehicle both orally and intravenously. At 90 minutes post-anti-CD3 antibody, rats were anesthetized and blood removed by terminal cardiac puncture. IL-2 levels were measured from plasma using the Rat IL-2 Quantikine ELISA Kit. Data are plotted as the mean \pm S.E. $* p<0.05$; $* * p<0.001$ versus positive control group (B) Relationship between inhibition of IL-2 release and seletalisib total blood concentration. For seletalisib bioanalysis, supernatant from blood samples was reconstituted, plated, and injected into a liquid chromatography coupled with tandem mass spectrometry system. 
data across experiments, demonstrated that seletalisib has potent in vivo effects with an estimated $\mathrm{IC}_{50}$ value of $<10 \mathrm{nM}$ (Fig. 6B).

\section{Discussion}

Seletalisib is a novel PI3K $\delta$ inhibitor with a high degree of biochemical selectivity to $\mathrm{PI} 3 \mathrm{~K} \delta$ compared with the other class I PI3K enzymes, and to non-PI3K kinases, nonkinase enzymes, and a panel of receptors and ion channels. Compared with data from published sources for idelalisib [ IC $_{50}$ values of $2.5,89,565$, and $820 \mathrm{nM}$ for $\mathrm{PI} 3 \mathrm{KK} \delta, \alpha, \beta$, and $\gamma$, respectively (Lannutti et al., 2011)] and duvelisib [IC I0 $_{50}$ values of 2.5, 27, 85, $1602 \mathrm{nM}$ for $\mathrm{PI} 3 \mathrm{~K} \delta, \alpha, \beta$, and $\gamma$, respectively (Winkler et al., 2013)], seletalisib is in a range of selectivity similar to the other class I PI3K enzymes but with greater selectivity toward the PI3K $\gamma$ and $\beta$ isoforms compared with duvelisib (Table 1). Seletalisib demonstrates good cellular activity, potently inhibiting phosphorylation of AKT following activation of the BCR in a B-cell line (Fig. 3A). In addition to its role downstream of tyrosine kinase receptors, it has emerged in recent years that $\mathrm{PI} 3 \mathrm{~K} \delta$ is also able to signal downstream of GPCRs (Okkenhaug, 2013b). It has been demonstrated previously that fMLP is able to activate neutrophils in a PI3K $\delta$-dependent manner through the GPCR formyl peptide receptor 1 (Condliffe et al., 2005). Seletalisib potently and fully inhibited fMLP-activated superoxide release from human neutrophils. To demonstrate that this effect was not through inhibition of other targets on the superoxide pathway, superoxide release was activated by PMA, which was not inhibited by seletalisib.

When profiled across a broad range of human primary cell systems (BioMAP), seletalisib showed activity in systems restricted to the adaptive immune system, consistent with its PI3K $\delta$-selective specificity. In the PBMC-containing BioMAP assays, seletalisib showed inhibition of proliferation and cytokine and IgG release with little or no signs of cytotoxicity. The lack of activity of seletalisib in non-leukocyte-containing BioMAP systems contrasted with the activities obtained with the pan-PI3K isoform inhibitor UCB1370037, which showed activity in all of the systems tested, reflecting the critical cellular roles of the ubiquitously expressed PI3K $\alpha$ and $\beta$ isoforms. The inhibition of fMLP-induced neutrophil superoxide release by seletalisib contrasted with lack of activity observed in macrophage readouts in the BioMAP profile. These data indicate that PI3K $\delta$ plays a restricted role in cells of the innate immune system and its relevance in these cell types to immune disease awaits elucidation. The selective functional activity of seletalisib in the broad range of cellular assays in the BioMAP profile is in accordance with our current understanding of the role of PI3K $\delta$ from genetic and pharmacological studies (Stark et al., 2015). Together with the biochemical data, these findings indicate that seletalisib is a potent and selective inhibitor of PI3K $\delta$ activity.

Studies using genetic ablation of PI3K $\delta$ in mouse cells have shown that $\mathrm{PI} 3 \mathrm{~K} \delta$ activity is required for the differentiation and function of T-cells (Okkenhaug et al., 2006). These findings have been supported by the use of PI3K $\delta$-specific inhibitors, such as IC87114 (Soond et al., 2010). Our findings show that seletalisib inhibits secretion of cytokines (IFN $\gamma$, IL-17, and TNF- $\alpha$ ) from human-donor PBMCs following TCR activation by crosslinking of the receptor. As an in vivo rat model was used to assess the systemic action of seletalisib, the functional activity of the compound was determined in rat PBMCs by measuring TNF- $\alpha$ levels following activation of the TCR. Seletalisib showed similar potency in the rat and human TNF- $\alpha$ release assays ( 22 and $31 \mathrm{nM}$, respectively), supporting the use of rat as the species for an in vivo mechanistic study. Furthermore, antigen-specific activation of T-cells from HDMallergic donors, measured by release of IL-5 and IL-13, was inhibited by seletalisib. The higher potency of seletalisib in the HDM-activated system compared with the anti-CD3 crosslinking system may reflect the more selective activation of T-cells caused by HDM allergen compared with anti-CD3. T-helper (Th) cells types 1 and 17 have been implicated in the pathogenesis of autoimmune diseases and chronic inflammatory disorders, and Th2 is acknowledged to have a pivotal role in human allergies [as reviewed by Cosmi et al. (2014)]. In a $\mathrm{T}$ cell-driven cytokine release model in the rat, seletalisib potently inhibited IL-2 release, demonstrating its activity in an in vivo setting. These data are consistent with a $\mathrm{PI} 3 \mathrm{~K} \delta$ selective mechanism in accordance with previous findings in both mouse and human systems using genetic and pharmacological approaches (Han et al., 2012).

$\mathrm{PI} 3 \mathrm{~K} \delta$ plays a central role in B-cell differentiation, expansion, and function. It is recruited upon activation of the BCR and the coreceptor CD19 and is required for full functioning of activating receptors such as CD40 and Toll-like receptors (TLRs), and cytokine receptors for B-cell activation factor and IL-6, for example (Limon and Fruman, 2012). Anti-IgM-driven cultures showed that seletalisib inhibits B-cell proliferation with a potency similar to the Ramos pAKT assay (26 and $15 \mathrm{nM}$, respectively). CpG signals through TLR9 and the potent activity of seletalisib in the CpG-activated cytokine release assay confirms the importance of PI3K $\delta$ in TLR signaling. Interestingly, the inhibition of cytokine release in this case is incomplete, indicating that TLR9 signaling is not solely dependent on PI3K $\delta$. B-cells have been shown to proliferate in the absence of $\mathrm{PI} 3 \mathrm{~K} \delta$, so despite this central role, there are compensating mechanisms that can be activated under certain circumstances (Fruman et al., 1999; Omori et al., 2006). To assess seletalisib activity in a more physiologic environment, a whole blood assay using CD69 as a marker of B-cell activation was developed. The potency of the compound in the assay $(57 \mathrm{nM})$ was similar to that achieved in the other in vitro assays carried out in which only fetal calf serum is present to provide a nonspecific binding component. There was sufficient unbound compound in human blood to allow potent inhibition of B-cell activation.

The ability of seletalisib to act in the whole blood compartment was further demonstrated by inhibition of basophil degranulation measured via CD63 expression. Degranulation was triggered by anti-IgE-mediated crosslinking of FceR1, which requires PI3K $\delta$ to signal (Okkenhaug et al., 2007). Seletalisib showed potent and complete inhibition of this system consistent with the absolute requirement for PI3K $\delta$ for FceR1-activated degranulation.

The selective inhibition of PI3K $\delta$ by seletalisib infers a potent effect specifically directed at the adaptive immune system by virtue of PI3K $\delta$ 's receptor coupling (Hawkins and Stephens, 2015). In particular, inhibition of PI3K $\delta$ by seletalisib could provide benefit to patients with autoimmune diseases that are driven by a dysregulated proinflammatory cytokine secretion, including rheumatoid arthritis, systematic lupus 
erythematosus, type-1 diabetes, psoriasis, and multiple sclerosis (Haylock-Jacobs et al., 2011; Puri and Gold, 2012). The recent discovery of activating mutations in the $\mathrm{p} 110 \delta$ catalytic domain and in the $\mathrm{p} 85 \alpha$ regulatory subunit in a group of primary immune deficiency patients provides a further rationale for the therapeutic use of PI3K $\delta$ inhibitors (Angulo et al., 2013; Deau et al., 2014; Lucas et al., 2014; Hawkins and Stephens, 2015). The high degree of selectivity achieved with seletalisib may allow sparing of the other PI3K isoforms, at the same time fully blocking PI3K $\delta$ activity, thereby avoiding potentially undesirable effects on immune cell functions unrelated to disease pathology.

Seletalisib has undergone clinical testing in healthy donors to assess its tolerability and pharmacokinetic and pharmacodynamic profile in healthy volunteers and patients with psoriasis (NCT02303509). It is currently being tested in patients with primary Sjögren's syndrome (NCT02610543). The utility of isoform-selective PI3K inhibitors for patients with autoimmune and inflammatory disease will emerge in the coming years as more data from clinical studies become available.

In conclusion, seletalisib is a new chemical entity that is a potent and selective inhibitor of PI3K $\delta$ with potential for the treatment of a range of immune-inflammatory and immunodeficiency diseases. The effects of seletalisib in more complex pharmacological disease models will be reported in future publications.

\section{Acknowledgments}

We thank Eugene Healy (University of Southampton) for his critical reading of the manuscript. Jen Timoshanko (UCB Pharma) provided editorial and publication support. Medical writing and editorial support was provided by Mark O'Connor, Stephen Paterson, and Emma Donadieu from, and on behalf of, iMed Comms, an Ashfield Company, part of UDG Healthcare plc.

\section{Authorship Contributions}

Conducted experiments: Allen, Brookings, Crosby, Cutler, Davies, McCluskey, Merriman, Powell, Shuttleworth, Tewari, Twomey, Watt, Payne.

Performed data analysis: Allen, Powell, Crosby, Cutler, Delgado, Fahy, Silva, Healy, Davies, McCluskey, Merriman, Kotian, Tewari, Watt, Payne.

Wrote or contributed to the writing of the manuscript: Allen, Brookings, Crosby, Cutler, Davies, Delgado, Fahy, Healy, Kotian, McCluskey, Merriman, Payne, Powell, Shuttleworth, Silva, Tewari, Twomey, Watt.

\section{References}

Al-Alwan MM, Okkenhaug K, Vanhaesebroeck B, Hayflick JS, and Marshall AJ (2007) Requirement for phosphoinositide 3-kinase p110delta signaling in B cell antigen receptor-mediated antigen presentation. J Immunol 178:2328-2335.

Ali K, Bilancio A, Thomas M, Pearce W, Gilfillan AM, Tkaczyk C, Kuehn N, Gray A, Giddings J, Peskett E, et al. (2004) Essential role for the p110delta phosphoinositide 3-kinase in the allergic response. Nature 431:1007-1011.

Ali K, Camps M, Pearce WP, Ji H, Rückle T, Kuehn N, Pasquali C, Chabert C, Rommel C, and Vanhaesebroeck B (2008) Isoform-specific functions of phosphoinositide 3-kinases: p110 delta but not p110 gamma promotes optimal allergic responses in vivo. J Immunol 180:2538-2544.

Angulo I, Vadas O, Garçon F, Banham-Hall E, Plagnol V, Leahy TR, Baxendale H, Coulter T, Curtis J, Wu C, et al. (2013) Phosphoinositide 3-kinase $\delta$ gene mutation predisposes to respiratory infection and airway damage. Science 342:866-871.

Banham-Hall E, Clatworthy MR, and Okkenhaug K (2012) The therapeutic potential for PI3K Inhibitors in autoimmune rheumatic diseases. Open Rheumatol $J$ 6: 245-258.

Bartok B, Boyle DL, Liu Y, Ren P, Ball ST, Bugbee WD, Rommel C, and Firestein GS (2012) PI3 kinase $\delta$ is a key regulator of synoviocyte function in rheumatoid arthritis. Am J Pathol 180:1906-1916.

Berg EL, Yang J, Melrose J, Nguyen D, Privat S, Rosler E, Kunkel EJ, and Ekins S (2010) Chemical target and pathway toxicity mechanisms defined in primary human cell systems. J Pharmacol Toxicol Methods 61:3-15.
Bilancio A, Okkenhaug K, Camps M, Emery JL, Ruckle T, Rommel C, and Vanhaesebroeck B (2006) Key role of the p110delta isoform of PI3K in B-cell antigen and IL-4 receptor signaling: comparative analysis of genetic and pharmacologic interference with p110delta function in B cells. Blood 107:642-650.

Bowes J, Brown AJ, Hamon J, Jarolimek W, Sridhar A, Waldron G, and Whitebread $\mathrm{S}$ (2012) Reducing safety-related drug attrition: the use of in vitro pharmacological profiling. Nat Rev Drug Discov 11:909-922.

Clayton E, Bardi G, Bell SE, Chantry D, Downes CP, Gray A, Humphries LA, Rawlings D, Reynolds H, Vigorito E, et al. (2002) A crucial role for the p110delta subunit of phosphatidylinositol 3-kinase in B cell development and activation. $J$ Exp Med 196:753-763.

Condliffe AM, Davidson K, Anderson KE, Ellson CD, Crabbe T, Okkenhaug K, Vanhaesebroeck B, Turner M, Webb L, Wymann MP, et al. (2005) Sequential activation of class IB and class IA PI3K is important for the primed respiratory burst of human but not murine neutrophils. Blood 106:1432-1440.

Cosmi L, Maggi L, Santarlasci V, Liotta F, and Annunziato F (2014) T helper cells plasticity in inflammation. Cytometry A 85:36-42.

Costa C, Martin-Conte EL, and Hirsch E (2011) Phosphoinositide 3-kinase p110 $\gamma$ in immunity. IUBMB Life 63:707-713.

Deau MC, Heurtier L, Frange P, Suarez F, Bole-Feysot C, Nitschke P, Cavazzana M, Picard C, Durandy A, Fischer A, et al. (2014) A human immunodeficiency caused by mutations in the PIK3R1 gene. J Clin Invest 124:3923-3928.

Dil N and Marshall AJ (2009) Role of phosphoinositide 3-kinase p110 delta in TLR4and TLR9-mediated B cell cytokine production and differentiation. Mol Immunol 46:1970-1978.

Flinn I, Oki Y, Patel M, Horwitz SM, Foss FM, Sweeney J, Allen K, Douglas M, Steelman L, Dunbar J et al. (2014) A Phase 1 evaluation of duvelisib (IPI-145), a PI3K- $\delta, \gamma$ inhibitor, in patients with relapsed/refractory iNHL Blood 124:802.

Foster JG, Blunt MD, Carter E, and Ward SG (2012) Inhibition of PI3K signaling spurs new therapeutic opportunities in inflammatory/autoimmune diseases and hematological malignancies. Pharmacol Rev 64:1027-1054.

Fruman DA, Snapper SB, Yballe CM, Davidson L, Yu JY, Alt FW, and Cantley LC (1999) Impaired B cell development and proliferation in absence of phosphoinositide 3-kinase p85alpha. Science 283:393-397.

Gracias DT, Boesteanu AC, Fraietta JA, Hope JL, Carey AJ, Mueller YM, Kawalekar OU, Fike AJ, June CH, and Katsikis PD (2016) Phosphatidylinositol 3-kinase p1108 isoform regulates CD8 + T cell responses during acute viral and intracellular bacterial infections. J Immunol 196:1186-1198.

Han JM, Patterson SJ, and Levings MK (2012) The role of the PI3K signaling pathway in CD4(+) T cell differentiation and function. Front Immunol 3:245.

Hawkins PT and Stephens LR (2015) PI3K signalling in inflammation. Biochim Biophys Acta 1851:882-897.

Haylock-Jacobs S, Comerford I, Bunting M, Kara E, Townley S, Klingler-Hoffmann M, Vanhaesebroeck B, Puri KD, and McColl SR (2011) PI3K $\delta$ drives the pathogenesis of experimental autoimmune encephalomyelitis by inhibiting effector $\mathrm{T}$ cell apoptosis and promoting Th17 differentiation. J Autoimmun 36:278-287.

Hebeis BJ, Vigorito E, and Turner M (2004) The p110delta subunit of phosphoinositide 3 -kinase is required for the lipopolysaccharide response of mouse B cells. Biochem Soc Trans 32:789-791.

Hutchinson G, Allen R, Alexander R, Cox M, Edwards C, Edwards H, Fetterman J, Franklin R, Gill A, Harris SJ et al.(2008) In vitro and in vivo activity of potent, selective inhibitors of PI3-kinase that lack mTOR activity, presented at AACR special meeting: Targeting the PI3-Kinase Pathway in Cancer; 2008 November 11-14; Cambridge, MA. American Association for Cancer Research, Philadelphia, PA.

Infinity Pharmaceuticals (Press release 2014): Infinity Reports Topline Data from Phase 2a Exploratory Study of Duvelisib in Patients with Mild, Allergic Asthma. Infinity Pharmaceuticals, Cambridge, MA.

Infinity Pharmaceuticals (Press release 2015) Infinity Reports Topline Results from Phase 2 Study of Duvelisib in Rheumatoid Arthritis. Infinity Pharmaceuticals, Cambridge, MA.

Ji H, Rintelen F, Waltzinger C, Bertschy Meier D, Bilancio A, Pearce W, Hirsch E, Wymann MP, Rückle T, Camps M, et al. (2007) Inactivation of PI3Kgamma and PI3Kdelta distorts T-cell development and causes multiple organ inflammation. Blood 110:2940-2947.

Jou ST, Carpino N, Takahashi Y, Piekorz R, Chao JR, Carpino N, Wang D, and Ihle JN (2002) Essential, nonredundant role for the phosphoinositide 3-kinase p110delta in signaling by the B-cell receptor complex. Mol Cell Biol 22: 8580-8591.

Kunkel EJ, Dea M, Ebens A, Hytopoulos E, Melrose J, Nguyen D, Ota KS, Plavec I, Wang Y, Watson SR, et al. (2004a) An integrative biology approach for analysis of drug action in models of human vascular inflammation. FASEB $J \mathbf{1 8}$ : 1279-1281.

Kunkel EJ, Plavec I, Nguyen D, Melrose J, Rosler ES, Kao LT, Wang Y, Hytopoulos E, Bishop AC, Bateman R, et al. (2004b) Rapid structure-activity and selectivity analysis of kinase inhibitors by BioMAP analysis in complex human primary cellbased models. Assay Drug Dev Technol 2:431-441.

Lannutti BJ, Meadows SA, Herman SE, Kashishian A, Steiner B, Johnson AJ, Byrd JC, Tyner JW, Loriaux MM, Deininger M, et al. (2011) CAL-101, a p110delta selective phosphatidylinositol-3-kinase inhibitor for the treatment of B-cell malignancies, inhibits PI3K signaling and cellular viability. Blood 117:591-594.

Limon JJ and Fruman DA (2012) Akt and mTOR in B cell activation and differentiation. Front Immunol 3:228.

Lucas CL, Chandra A, Nejentsev S, Condliffe AM and Okkenhaug K (2016) PI3Kס and primary immunodeficiencies. Nat Rev Immunol 16:702-714.

Lucas CL, Kuehn HS, Zhao F, Niemela JE, Deenick EK, Palendira U, Avery DT, Moens L, Cannons JL, Biancalana M, et al. (2014) Dominant-activating germline mutations in the gene encoding the PI(3)K catalytic subunit p1108 result in T cell senescence and human immunodeficiency. Nat Immunol 15:88-97.

Okkenhaug K (2013a) Rules of engagement: distinct functions for the four class I PI3K catalytic isoforms in immunity. Ann N Y Acad Sci 1280:24-26. 
Okkenhaug K (2013b) Signaling by the phosphoinositide 3-kinase family in immune cells. Annu Rev Immunol 31:675-704.

Okkenhaug K, Ali K, and Vanhaesebroeck B (2007) Antigen receptor signalling: a distinctive role for the p110delta isoform of PI3K. Trends Immunol 28:80-87.

Okkenhaug K, Bilancio A, Farjot G, Priddle H, Sancho S, Peskett E, Pearce W, Meek SE, Salpekar A, Waterfield MD, et al. (2002) Impaired B and T cell antigen re ceptor signaling in p110delta PI 3-kinase mutant mice. Science 297:1031-1034.

Okkenhaug K, Patton DT, Bilancio A, Garçon F, Rowan WC, and Vanhaesebroeck B (2006) The p110 $\delta$ isoform of phosphoinositide 3-kinase controls clonal expansion and differentiation of Th cells. J Immunol 177:5122-5128.

Okkenhaug K, Turner M, and Gold MR (2014) PI3K signaling in B cell and T cell biology. Front Immunol 5:557.

Omori SA, Cato MH, Anzelon-Mills A, Puri KD, Shapiro-Shelef M, Calame K, and Rickert RC (2006) Regulation of class-switch recombination and plasma cell differentiation by phosphatidylinositol 3-kinase signaling. Immunity 25:545-557.

Patel MR, O’Brien SM, Faia K, White K, Douglas M, Allen K, Kutok JL, Sweeney J, Kelly V, Flinn I et al. (2015) Early clinical activity and pharmacodynamic effects of duvelisib, a PI3K- $\delta, \gamma$ inhibitor, in patients with treatment-naive CLL. J Clin Oncol 33 (suppl; abstr 7074)

Pinho JF, Medeiros MA, Capettini LS, Rezende BA, Campos PP, Andrade SP, Cortes SF, Cruz JS, and Lemos VS (2010) Phosphatidylinositol 3-kinase- $\delta$ up-regulates L-type $\mathrm{Ca} 2+$ currents and increases vascular contractility in a mouse model of type 1 diabetes. Br J Pharmacol 161:1458-1471.

Puri KD and Gold MR (2012) Selective inhibitors of phosphoinositide 3-kinase delta: modulators of B-cell function with potential for treating autoimmune inflammatory diseases and B-cell malignancies. Front Immunol 3:256.
Rommel C, Camps M, and Ji H (2007) PI3K delta and PI3K gamma: partners in crime in inflammation in rheumatoid arthritis and beyond? Nat Rev Immunol 7 : 191-201.

Somoza JR, Koditek D, Villaseñor AG, Novikov N, Wong MH, Liclican A, Xing W, Lagpacan L, Wang R, Schultz BE, et al. (2015) Structural, biochemical, and biophysical characterization of idelalisib binding to phosphoinositide 3-kinase $\delta . J$ Biol Chem 290:8439-8446.

Soond DR, Bjørgo E, Moltu K, Dale VQ, Patton DT, Torgersen KM, Galleway F, Twomey B, Clark J, Gaston JS, et al. (2010) PI3K p110delta regulates T-cell cytokine production during primary and secondary immune responses in mice and humans. Blood 115:2203-2213.

Stark AK, Sriskantharajah S, Hessel EM, and Okkenhaug K (2015) PI3K inhibitors in inflammation, autoimmunity and cancer. Curr Opin Pharmacol 23:82-91.

Suárez-Fueyo A, Barber DF, Martínez-Ara J, Zea-Mendoza AC, and Carrera AC (2011) Enhanced phosphoinositide 3-kinase $\delta$ activity is a frequent event in systemic lupus erythematosus that confers resistance to activation-induced $\mathrm{T}$ cell death. J Immunol 187:2376-2385.

Winkler DG, Faia KL, DiNitto JP, Ali JA, White KF, Brophy EE, Pink MM, Proctor JL, Lussier J, Martin CM, et al. (2013) PI3K- $\delta$ and PI3K- $\gamma$ inhibition by IPI-145 abrogates immune responses and suppresses activity in autoimmune and inflammatory disease models. Chem Biol 20:1364-1374.

Address correspondence to: Dr. Rodger Allen, UCB Pharma Ltd., 216 Bath Road, Slough, Berkshire, SL1 4EN, UK. E-mail: rodger.allen@ucb.com 